\title{
APPLICATION OF THE HLD VALUE IN THE PETROLEUM INDUSTRY
}

\author{
Roland NAGY1 ${ }^{1}$ Péter LENDVAI ${ }^{2}$, Réka KOTHENCZ³ ${ }^{3}$ László BARTHA ${ }^{4}$ \\ University of Pannonia, Faculty of Engineering, Institutional Department of MOL Hydrocarbon and Coal \\ Processing, Veszprém, Hungary \\ ${ }^{1}$ nroland@almos.uni-pannon.hu \\ 2peti.lendvai1993@gmail.com \\ ${ }^{3}$ kothenczr@almos.uni-pannon.hu \\ ${ }^{4}$ bartha@almos.uni-pannon.hu
}

\begin{abstract}
The efficiency of demulsification is a key process in terms of extracting the oil of $\mathrm{O} / \mathrm{V}$ (oil-in-water type) emulsions of enhanced oil recovery. Consequently, the separation of emulsion systems and the recovery of the maximum amount of oil from the colloid system play an important role in the petroleum industry. The stability of the emulsions from oil recovery is influenced by numerous factors. J. L. Salager developed the HLD (Hydrophilic-Lipophilic Deviation) equation in order to examine the efficiency of demulsification. Our aim was to investigate whether the equation developed by Salager is suitable for monitoring the stability of petroleum industrial emulsions.
\end{abstract}

Keywords: enhanced oil recovery, demulsification, HLD value

\section{Introduction}

Emulsions are indispensable in most industrial technologies. Disperse systems play a significant role in the industry and in different life processes. The process of emulsification and demulsification plays an important role in producing, and in dissociating emulsions [1, 2].

Various parameters affect the stability of dispersion systems during demulsification. These parameters may be: salt concentration, temperature, $\mathrm{pH}$, water and oil phase composition, agitation rate and duration, emulsifying or demulsifying agent concentration, drop size and distribution [3].

During demulsification in the petroleum industry, crude oil is separated from the aqueous phase. Various mechanisms may be employed for the demulsification of disperse systems which are shown in Figure 1. [4].

The most widespread method of emulsification is adding the demulsifier to the dispersion. It is possible to add different salts (e.g. aluminium or iron salts) to the system for chemical demulsification [5]. The most essential function of chemical demulsifiers used in $\mathrm{O} / \mathrm{V}$ dispersion systems is to obtain the maximum possible amount of crude oil.

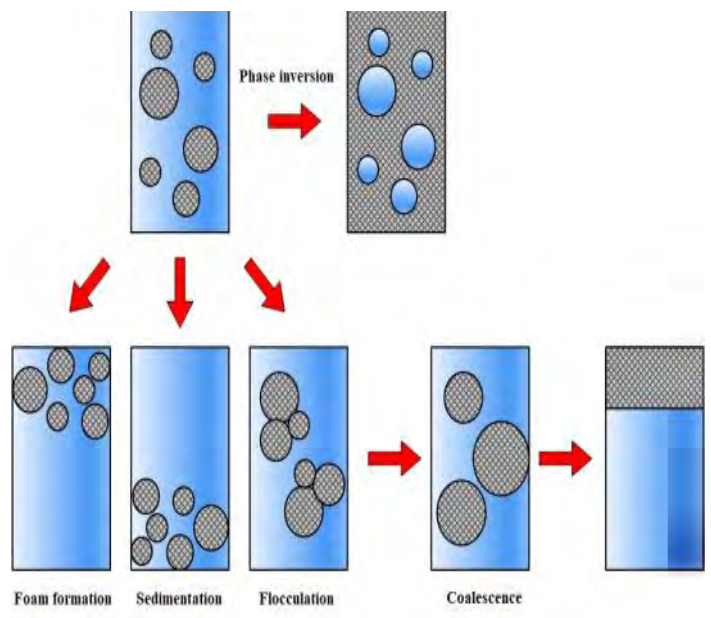

Figure 1. Process of demulsification 
Our aim was to investigate the separation of the $\mathrm{O} / \mathrm{V}$ emulsion systems produced in enhanced oil recovery and the applicability of HLD value in order to obtain the maximum amount of oil content of the colloid system. Furthermore, our goal was to investigate whether the HLD value is suitable for monitoring the demulsification process.

\section{Definition of HLD value}

J. L. Salager has generalized the equation of thermodynamic surfactant affinity (SAD), which helps to characterize macro- and microemulsion systems. This value is an empirical correlation, the HLD (Hydrophilic Lipophilic Deviation). It can be calculated by a dimensionless equation which was found suitable for characterizing the stability of emulsions. Contrary to HLB, which only covers the surfactant, the HLD equation incorporates most stability factors such as surfactant and oil phase properties, salt content and concentration, temperature and pressure [6, 7].

$\mathrm{O} / \mathrm{V}$ type emulsions containing ionic surfactants usually have a negative HLD value. The emulsion is the least stable when the HLD approaches zero, as there is no difference between hydrophilic and lipophilic interactions. Demulsifiers are able to influence this.

Studies have shown that the concentration of the demulsifying agent can affect stability more than expected. The surfactant is not able to break the surfactant film at a lower concentration than optimal. However, if the demulsifier concentration is higher than optimum, the opposite effect is achieved and the emulsion becomes more stable [6, 7].

Basically, two forms of the HLD equation have been developed; one characterizes the systems where the surfactants are non-ionic (1) and the other when they are ionic (2) [8].

$$
\begin{aligned}
& H L D=\alpha-E O N+b(\text { salt })-k A C N+t \triangle T+a A \\
& H L D=\sigma+\ln (\text { salt })-k A C N+t \Delta T+a A
\end{aligned}
$$

where:

$E O N$ : number of "ethylene oxide" groups of the ethoxylated non-ionic surfactants

salt: salinity expressed as a percentage by weight of $\mathrm{NaCl}$

$A C N$ : the carbon number of the n-alkyl chain of the surfactant

$\Delta T$ : temperature difference from the reference temperature $\left(25^{\circ} \mathrm{C}\right)$
$A$ : quantity of added alcohol expressed in $\mathrm{m} / \mathrm{m} \%$

$\sigma, \alpha, k, t$ : parameters of the surfactant

$a$ : constant of alcohol and surfactant

$b$ : constant of the salt

HLD is, therefore, therefore a result of comprehensive conceptual calculations that include all the major physico-chemical properties which helps to predict the effect of each variable. All parameters of the equation can be easily and practically quantified.

\section{Application of HLD value in the pet- roleum industry}

During enhanced oil recovery the surface active surfactants form an emulsion with the brine and the crude oil while reducing the interfacial tension. Thus, the oil particles are washed through the pores then an emulsion is formed and produced through the production well.

Our goal was also to determine the applicability of HLD value when using different types of demulsifiers.

The HLD value was first calculated for a model emulsion which contained surfactants (coconut fatty acid-DEA, SDBS), butoxyethanol $(0.6 \mathrm{~m} / \mathrm{m} \%)$, model oil (95 V/V\%) and model brine (5 V/V\%). In our measurements, the effect of a polyvalent salt, a linear alcohol with high carbon number, a surfactant (ethoxylate derivative) and different demulsifiers were investigated at various concentrations.

The following equation was applied for the HLD of the standard emulsion:

$$
\begin{aligned}
H L D= & \left(x_{i} * \alpha_{i}+x_{i} * \sigma_{i}\right)+\sum x_{i} \ln \left(\text { salt }_{i}\right) \\
& -\sum x_{i} k_{i} A C N+t \Delta T+a A
\end{aligned}
$$

where:

salt: salinity expressed as a percentage by weight

$A C N$ : the average carbon number of the n-alkyl chain of the surfactant

$\Delta T$ : temperature difference from the reference temperature $\left(25^{\circ} \mathrm{C}\right)$

$A$ : quantity of added alcohol expressed in $\mathrm{m} / \mathrm{m} \%$

$\sigma, \alpha, k, t$ : parameters of the sutfactantsurfactant

a: constant of alcohol and surfactant

$x$ : mole fractions of the components

Applying the above equation, the HLD of the demulsifyingfree standard emulsion was -5.94 . Since the HLD value is negative, an O/V disperse system is probable [8], which have been also con- 
firmed by our previous rheological tests [9]. The value shows that this system has a very a high stability.

The polyvalent salt, the linear alcohol and the surfactant (ethoxylate derivative) demulsifiers were added to the model emulsion in different concentrations and then the HLD value was calculated.

The results of the effect of the applied demulsifiers arewere compared in Figure 2.

Figure 2. shows that a much lower concentration of polyvalent salt is sufficient to achieve the desired effect. The other two demulsifiers have significantly reduced the stability of the emulsion, but the amount of excess also shows the advantages of the polyvalent salt.

In order to investigate the effectiveness of demulsification, the demulsifying factor (DF) was introduced which is the quotient of the separated oil/ original oil content (Table 1.).

Based on the results, it was found that the HLD correlation is suitable for characterizing the separation of emulsions containing salts, alcohols and

Table 1. Demulsifying factor for different types of demulsifiers

\begin{tabular}{|l|c|c|}
\hline $\begin{array}{c}\text { Type of } \\
\text { demulsifier }\end{array}$ & $\begin{array}{c}\text { Demulsifier } \\
\text { concentration }\end{array}$ & DF \\
\hline Polyvalent salt & $0.2 \mathrm{~m} / \mathrm{m} \%$ & 1.00 \\
\hline Linear alcohol & $0.2 \mathrm{~m} / \mathrm{m} \%$ & 0.90 \\
\hline Ethoxylate derivative & $0.2 \mathrm{~m} / \mathrm{m} \%$ & 0.85 \\
\hline
\end{tabular}

several surfactants. The stability of disperse systems can be followed at different demulsifier concentrations. The demulsifiers reduced differently the stability of the colloid system.

\section{Conclusions}

Our measurements have shown that the correlation of HLD value may be suitable for the prior characterization of the stability of disperse systems containing polyvalent salts, alcohol and surfactant demulsifiers. Combining the various saline compounds with organic and/or polymeric compounds can increase the efficiency of oil recovery of $\mathrm{O} / \mathrm{V}$ emulsions.

\section{References}

[1] Schramm L. L.: Emulsions, Foams, and Suspensions: Fundamentals and Applications. Wiley, Calgary, 1992.

[2] Becher P.: Emulsions: Theory and Practice. Reinhold Publishing Corporation, New York, 1965.

[3] Möbius D., Miller R., Fainerman V. B.: Surfactants: Chemistry, Interfacial Properties, Applications. Elsevier Science, Amsterdam, 2001.

[4] Rajakovic V., Skala D.: Separation of water-in-oil emulsions by freeze/thaw method and microwave radiation. Separation and Purification Technology, 49/2. (2006) 192-196.

https://doi.org/10.1016/j.seppur.2005.09.012

[5] Daniel J. F: The Nalco Water Handbook. Nalco Company, Third Edition, chapter 11 Emulsion Breaking, 2009

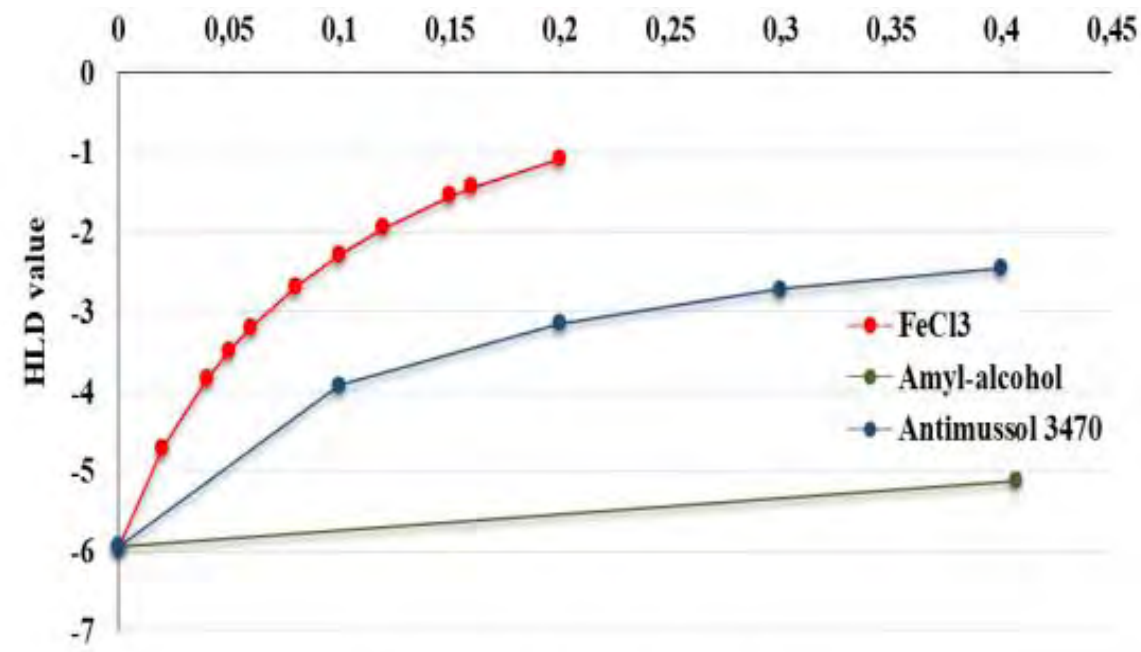

Concentration of demulsifier, $w \%$

Figure 2. HLD values of three types of demulsifiers at different concentrations 
[6] Salager J. L.: Microemulsions. In: Handbook of Detergents (Ed. Broze G.: ), Marcel Dekker, New York, 1999.

[7] Salager J. L.: Emulsion phase inversion phenomena. In: Emulsions and emulsion stability, (Ed. Sjöblom, J.) CRC Press, New York, 2006.

[8] Salager J. L., Antón R.E., Andérez J. M., Aubry J-M.: Formulation des micro-émulsions par la méthode du HLD. Techniques de l'Ingénieur, traité Génie des Procédés, 157. (2001) 1-20.

[9] Nagy R., Elekes A., Bartha L., Vágó, Á.: Rheological characterization of crude oil-water emulsions. Építőanyag - Journal of Silicate Based and Composite Materials 68/4. (2016) 98-104. 